\title{
Quantitative Analysis of Nerve Fibre Densities in the Cochlea of the House Mouse (Mus musculus)
}

\author{
GÜNTER EHRET : \\ Fachbereich Biologie, Universität Konstanz, Postfach 7733, D-7750 Konstanz, \\ Federal Republic of Germany
}

\begin{abstract}
Transverse sections of the cochlear nerve, silver-stained surface preparations of the cochlea, and silver- and osmium-stained tangential sections of the cochlea of the house mouse were made to determine the number and density of nerve fibres entering the organ of Corti and their distribution to inner and outer hair cells along the cochlear spiral. A number of $12,578 \pm 819$ fibres was counted within the cochlear nerve, which is almost equal to the total number of $12,350 \pm 810$ fibres entering the organ of Corti. The 12,350 fibres divide into $9,780(\hat{=} 79 \%)$ fibres running to the inner hair cells, $703(\hat{=} 6 \%)$ basilar (afferent) fibres and $1,867(\hat{=} 15 \%)$ upper tunnel radial (efferent) fibres innervating the outer hair cells. About $93 \%$ of all afferent fibres are connected to the inner hair cells, and only $7 \%$ innervate outer hair cells. The density of fibres running to the inner hair cells varies considerably and has a significant $(\mathrm{p}<0.01$ ) absolute and relative maximum $3.7 \mathrm{~mm}$ and $2.9 \mathrm{~mm}$ from the apex respectively (total length: $6.84 \mathrm{~mm}$ ) and decreases toward apex and base. The density of afferent fibres running to the outer hair cells shows a slow increase up to $2 \mathrm{~mm}$ from the apex, and remains on a constant low level (5.5 fibres per $40 \mu \mathrm{m})$ down to the base. The density of efferent fibres running to the outer hair cells increases linearly up to about $2 \mathrm{~mm}$ from the apex, remains rather constant ( 10 fibres per $40 \mu \mathrm{m}$ ) from $2 \mathrm{~mm}$ to $4 \mathrm{~mm}$, and then decreases toward the base. Generally, the outer hair cells show a convergent innervation pattern, the inner hair cells a divergent one. The significance of the present measurements is discussed in relation to respective results from other mammals and in relation to auditory thresholds.
\end{abstract}

There are two auditory receptor systems within the cochlea of mammals, the inner and outer hair cells, which have afferent and efferent nerve supplies (the sympathetic nerves will not be considered in this context). Numerous authors describe the innervation patterns of afferent and efferent fibres in relation to both types of receptor cells (e.g., Lorente de Nó, '37; Fernandez, '51; Spoendlin and Gacek, '63; Spoendlin, '70; Perkins and Morest, '75; Smith, '75). The studies showed a significant difference between the innervation pattern of inner and outer hair cells, and a variation in innervation density between apex and base of the cochlea. The courses of single fibres and their synaptic contacts with the hair cells were investigated. This kind of investigation, however, can give only qualitative information about fibre densities in different parts of the cochlea, although single fibres are traced very accurately.

Quantitative analyses of nerve fibre densities between apex and base of a cochlea exist only for cats (Spoendlin, '72, '73) and guinea pigs (Morrison et al., '75). In these studies the number of places along the cochlea where fibres were counted was very small, with six counts for the $22 \mathrm{~mm}$ long cochlea of the cat, and only three counts for the $20 \mathrm{~mm}$ long cochlea of the guinea pig. It is evident that a detailed analysis of fibre densities with a high resolution along the length of a mammalian cochlea is lacking. On the basis of such an analysis, however, the relative amount of information expressed as the number of affer-

1 Address from April, '78 to March, '79: Section of Neurobiology \& Behavior, 109 Langmuir Laboratory, Cornell University, Ithaca, Behavior, 109 Langmuir
New York 14853, U.S.A. 
ent fibres originating from a given place within the cochlea can be estimated and used as an input to further processing in higher centers of the brain. On the other hand, the number of efferent fibres is an indicator of the possible central influence on the hair cells. In addition it would be highly interesting to know something about the functional significance of different innervation densities at different places within the cochlea, by comparing innervation density, frequency representation along the basilar membrane, and auditory thresholds.

The present measurements on fibre densities within the cochlea of the house mouse were carried out to demonstrate: (a) the range of fibre variation in the cochlea of this mammal; (b) in comparison with the results from the cat, whether mammals which have large differences in cochlear lengths and thus in number of hair cells, differ in their innervation characteristics; (c) the possible direct influence of fibre densities on auditory thresholds in the house mouse, which have already been determined in several behavioral studies (Ehret, '74, '75a,b, '76).

\section{MATERIALS AND METHODS}

\section{Subjects}

Altogether 43 cochleae from male white laboratory mice (Mus musculus, outbred strain NMRI) aged four to ten weeks were examined. No deficiencies in hearing or structural abnormalities of the acoustic system are known in these mice so far.

\section{Cochlea preparation}

Animals were anaesthetized by ether, decapitated, and both cochleae including a portion of the bony labyrinth were quickly removed. Then different methods of fixation and further processing followed according to the measurements in question.

\section{(a) Silver-stained surface preparations}

The cochlea was immersed in $10 \%$ neutral formalin, the round and oval windows were carefully opened, and a small aperture was made at the apex. A thin setting pin fixed in a snap fastener of a small glass was then used to suspend the specimen in 10\% neutral formalin. Fixation was continued for two days at room temperature. Then the cochlea decalcified in 5\% trichloroacetic acid for two hours at $5^{\circ} \mathrm{C}$. After washing twice in distilled water, the one and one-half turns of the cochlea were carefully dissected into three or four portions. The staining technique used on the specimens was a modification of that described by Wright ('75). The portions of the cochlea were put into a solution of $1 \mathrm{ml} 1 \%$ silver nitrate $+0.5 \mathrm{ml} 10 \%$ pyridine $+48.5 \mathrm{ml}$ distilled water with a $\mathrm{pH}$ of 6.5-7 for six days at $37^{\circ} \mathrm{C}$. Without washing, they were put into a solution containing $10 \%$ sodium sulfite and $1 \%$ hydroquinone for ten minutes at $20^{\circ} \mathrm{C}$. A brief wash in $10 \%$ sodium chloride followed and then a transfer into a fresh solution of $10 \%$ sodium sulfite and $1 \%$ hydroquinone for ten minutes at $20^{\circ} \mathrm{C}$. The specimens were briefly washed in $10 \%$ sodium choloride followed by a thorough washing in distilled water. Finally the specimens were dehydrated and embedded in eukitt.

Such preparations were used to count fibres crossing the tunnel of Corti (upper tunnel radial fibres, basilar fibres, see fig. 1).

\section{(b) Silver-stained semi-thin sections}

For the basilar fibres cannot be quantitatively measured over larger distances in surface preparations, another method was used. The silver-stained and dehydrated specimens were embedded into "Spurr low-viscosity medium" and then cut tangentially (fig. 1, sectioning plane B) to the cochlear spiral on an ultramicrotome (Reichert OMU3). Before $3-\mu \mathrm{m}$ sections were made, the length of each cochlear segment was measured. Thus, the exact distance from the apex of the cochlea was determined for every cochlear section and every fibre count. During sectioning the portions of the cochlea were successively reorientated on the ultramicrotome to guarantee series of tangential sections throughout the whole cochlea. In a given series of tangential sections, a distance of $250-600 \mu \mathrm{m}$ of the organ of Corti could be examined depending on the curvature of the cochlear spiral at that location.

In these tangential sections, the upper tunnel radial fibres and the basilar fibres are transversely sectioned and can be counted.

(c) Glutaraldehyde-osmic acid fixationstaining and semi-thin sectioning

The preparation of a cochlea was conducted as before. However, the entire cochlea was put into a fixative consisting of equal parts of $6 \%$ glutaraldehyde and $0.5 \mathrm{M}$ phosphate buffer and containing $5 \%$ sucrose. Fixation continued for one and one-half hours at $20^{\circ} \mathrm{C}$. After washing in distilled water, the cochlea was de- 


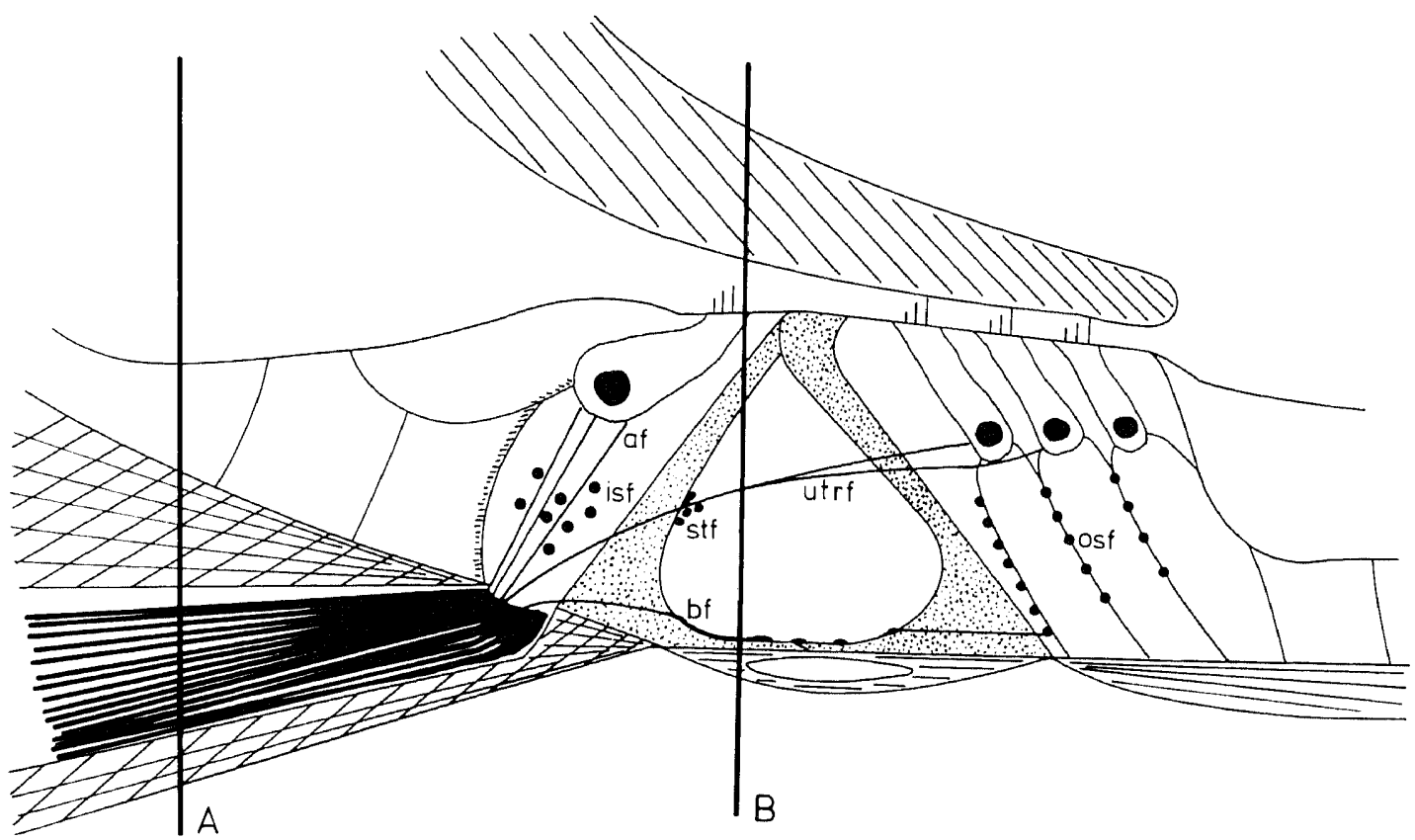

Fig. 1 This diagram of a radial section through the cochlea of the house mouse shows the different kinds of nerve fibres which are examined in the present study. Also two sectioning planes for tangential sections (A, B) are indicated. af, afferent fibres to the inner hair cells; isf, inner spiral fibres; stf, spiral tunnel fibres; utrf, upper tunnel radial fibre; bf, basilar fibre; osf, outer spiral fibres in continuation of basilar fibres.

calcified in $5 \%$ trichloroacetic acid for two and one-half hours at $5^{\circ} \mathrm{C}$. The cochlea was washed thoroughly and put into the fixative for another one-half hour. The cochlea was then carefully dissected into three or four portions, washed in distilled water, and put into a solution consisting of equal parts of $5 \%$ osmic acid and $0.2 \mathrm{M}$ phosphate buffer and containing $5 \%$ sucrose. Fixation was carried out at $0^{\circ} \mathrm{C}$ for two hours. After washing in distilled water, the specimens were dehydrated and embedded into Spurr low viscosity medium. The length of each specimen was measured and the portions of the cochlea were cut tangentially to the cochlear spiral (fig. 1, sectioning planes A and $\mathrm{B}$ ) in $3-\mu \mathrm{m}$ sections.

In these sections, the upper tunnel radial fibres and, when clearly distinguishable, the basilar fibres were counted. In addition, the number of all fibres was counted in the osseous spiral lamina just before they entered the organ of Corti through the habenula perforata.

\section{Cochlear nerve preparation}

The skull of a decapitated animal was opened and a large part of the forebrain was quickly removed while immersed in the glutaraldehyde fixative described above. After making a sagittal cut, the two halves of the brain were extracted together with the related cochlear capsules and put into a fresh solution of glutaraldehyde fixative for one hour at $20^{\circ} \mathrm{C}$. All nervous tissue except a small part where the VIIIth nerve entered the brain was removed, and the specimen was replaced in the fixative for another two hours. After washing thoroughly in $0.05 \mathrm{M}$ phosphate buffer, the specimen was decalcified in $5 \%$ trichloroacetic acid $\left(2\right.$ hours at $\left.5^{\circ} \mathrm{C}\right)$, washed in $0.05 \mathrm{M}$ phosphate buffer, fixed in glutaraldehyde fixative $\left(0.5\right.$ hour at $\left.20^{\circ} \mathrm{C}\right)$, and washed in the phosphate buffer. The specimen was then fixed in the osmic acid solution for 16 hours at $0^{\circ} \mathrm{C}$. Washing in distilled water, dehydration, and embedding in Spurr followed. The VIIIth nerve was cut transversely in $3-\mu \mathrm{m}$ sections.

\section{Measurements}

\section{(a) General}

The length of a portion of a cochlea was measured along the pillar cells over successive parts each maximally $300 \mu \mathrm{m}$. All measure- 


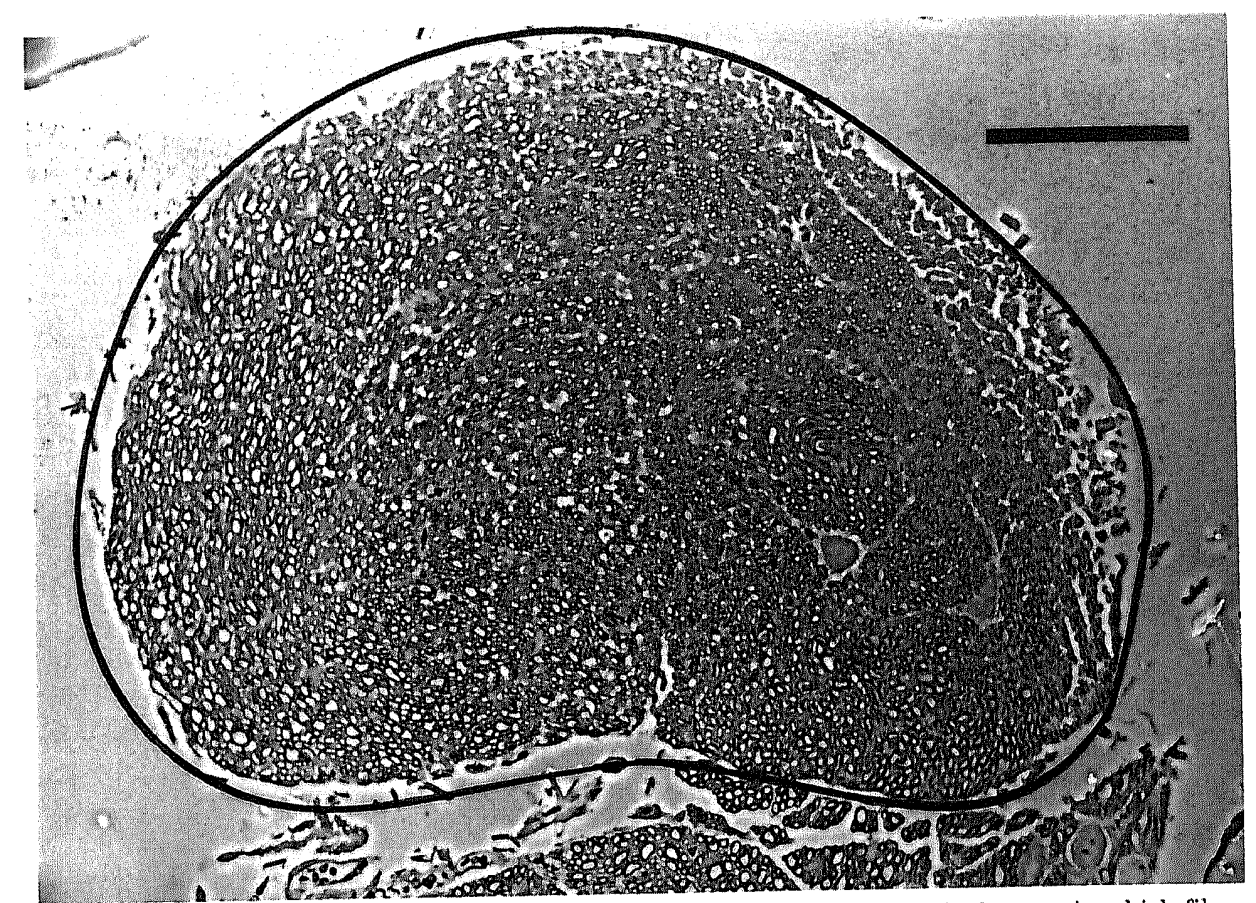

Fig. 2 Transverse section through the cochlear nerve. The black line surrounds the area in which fibres were counted. At the lower margin of the picture fibres are seen, which are most probably vestibular fibres (compare: Rasmussen, ' 40 ). Magnification of the microscope $\times 200$, marker $\stackrel{\hat{=}}{=} 100 \mu \mathrm{m}$.

ments were started at the apex of a cochlea, which was equal to $0 \mathrm{~mm}$.

The fibres were always counted in successive $40 \mu \mathrm{m}$ segments along the cochlea using an objective magnification of $80 \times$ (objective $40 \times$ oil, optovar $z \%$ ). When there were fibres on the border between two parts they were added to the number of the one in which the major area of the fibre was seen. All lengths were measured with a calibrated ocular micrometer ( $1 \mathrm{~cm}$ divided into 100) inserted into a $10 \times$ ocular.

Osmium preparations were always observed by using phase contrast.

\section{(b) Cochlear fibres}

Fibres were counted in six cochlear nerves. A quadratic grid $(5 \mathrm{~mm} \times 5 \mathrm{~mm}$, divided into 100 equal squares) inserted into a $10 \times$ ocular was used. The objective magnification was $200 \times$ (objective $100 \times$ oil, optovar $2 \times$ ). Only fibres within the cochlear portion of the VIIIth nerve, which are clearly separate from vestibular fibres (fig. 2), were counted. In each nerve 25 samples from the whole cross-sectional area were counted. The numbers of fibres of the samples were averaged and the fibre number calculated for the total area of the respective cochlear nerve.

\section{(c) Upper tunnel radial fibres (utrfs)}

Two different kinds of preparations were used for counting upper tunnel radial fibres: silver-stained surface preparations (figs. 3,4 ) and Spurr's embedded specimens which were tangentially sectioned (fig. 1, sectioning plane B; fig. 5).

In surface preparations 20 cochleae were evaluated; in five of them, however, only the most basal $1.5 \mathrm{~mm}$ was used. Fibres were only counted at places without any tissue distortions. As utrfs often cross the tunnel of Corti in fibre bundles, the roots of these bundles were always counted. In most cases they could be traced back to the inner spiral bundle below the inner hair cells (figs. 1, 4). Thus, it is possible to count single fibres reliably, before they cross the tunnel of Corti and branch among the outer hair cells (figs. 3, 4).

In tangential sections 17 cochleae were evaluated, in five of them, however, only the part between $2.5 \mathrm{~mm}$ and $4.5 \mathrm{~mm}$ from the apex was used. Sometimes it was difficult to determine the number of single fibres within a 


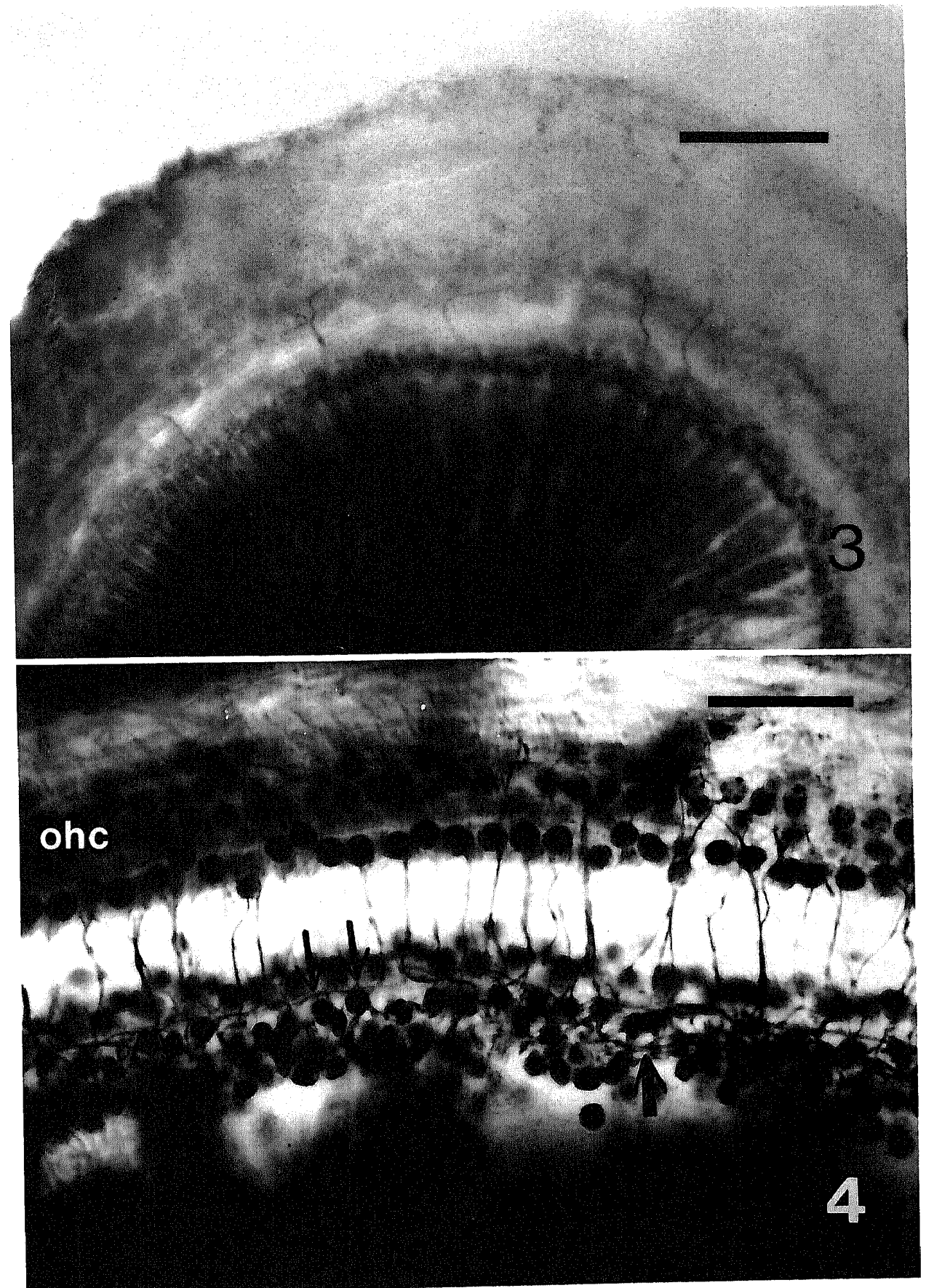

Fig. 3 Silver-stained surface preparation of the apical part of the cochlea. Very few upper tunnel radial (efferent) fibres can be seen branching in the area of the outer hair cells. Magnification $\times 200$, marker $\hat{=}$ $100 \mu \mathrm{m}$.

Fig. 4 Silver-stained surface preparation about $2.5 \mathrm{~mm}$ from the apex. Many bundles of upper tunnel (the inner spiral radial fibres cross) the tunnel of Corti. The rots cells. The spiral tunnel fibres are also visible (two arrows). ohc, outer fibres (one arrow) below the inner hair cells. 

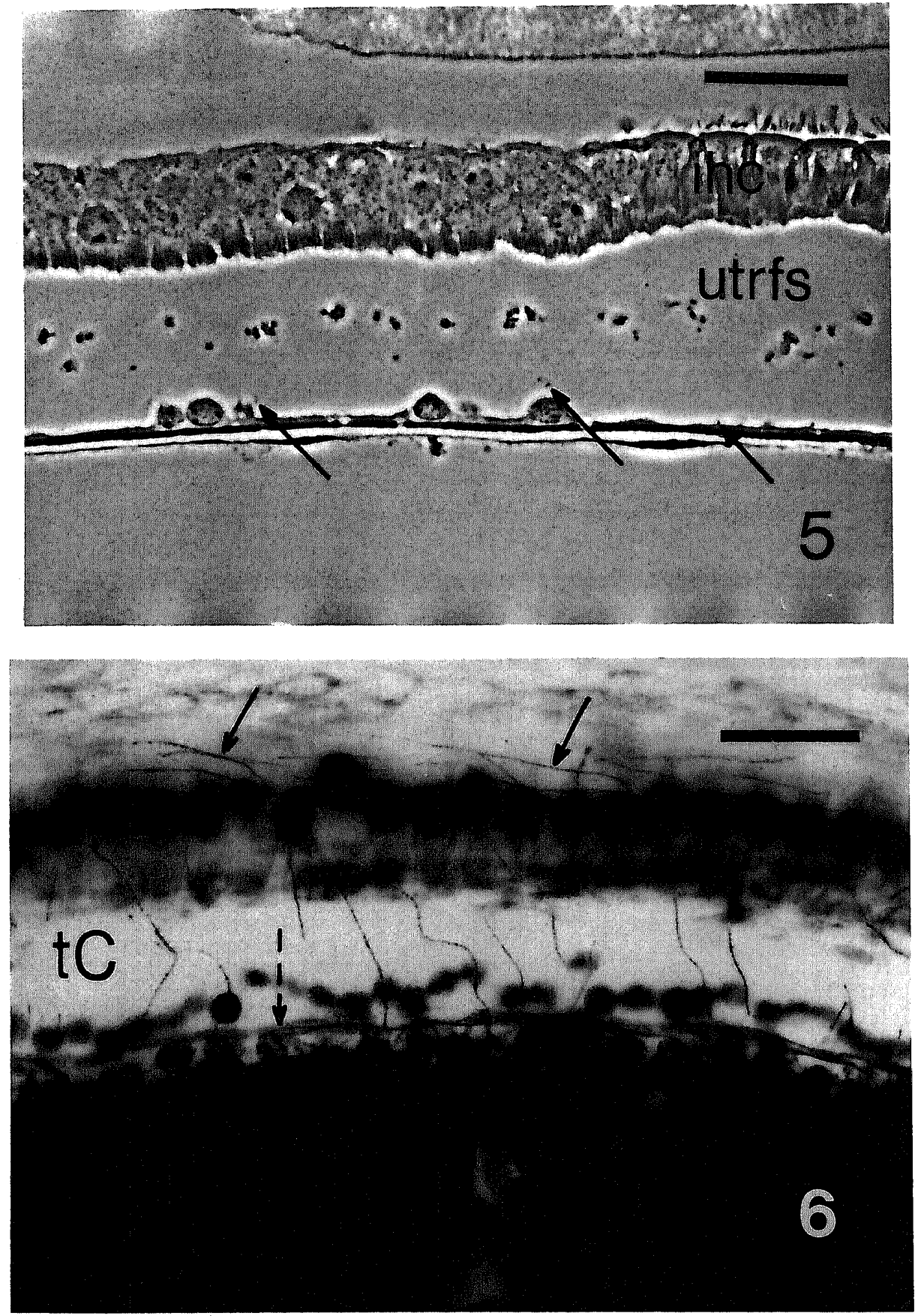

Fig. 5 Tangential section through the cochlea (osmium stain) about $2.6 \mathrm{~mm}$ from the apex. Upper tunnel radial fibres (utrfs) are transversely sectioned. Some transversely sectioned basilar fibres are also visible (arrows). Basilar fibres can be better identified under the microscope by varying the focus. ihc, inner hair cell. Magnification $\times 800$, marker $=25 \mu \mathrm{m}$.

Fig. 6 Silver-stained surface preparation about $2 \mathrm{~mm}$ from the apex. Basilar fibres cross the tunnel of Corti $(t C)$ and run basalward as the outer spiral fibres (arrows). The broken arrow points to the spiral tunnel fibres. The basilar fibres are slightly retouched for better visibility. Magnification $\times 640$, marker $=30 \mu \mathrm{m}$. 

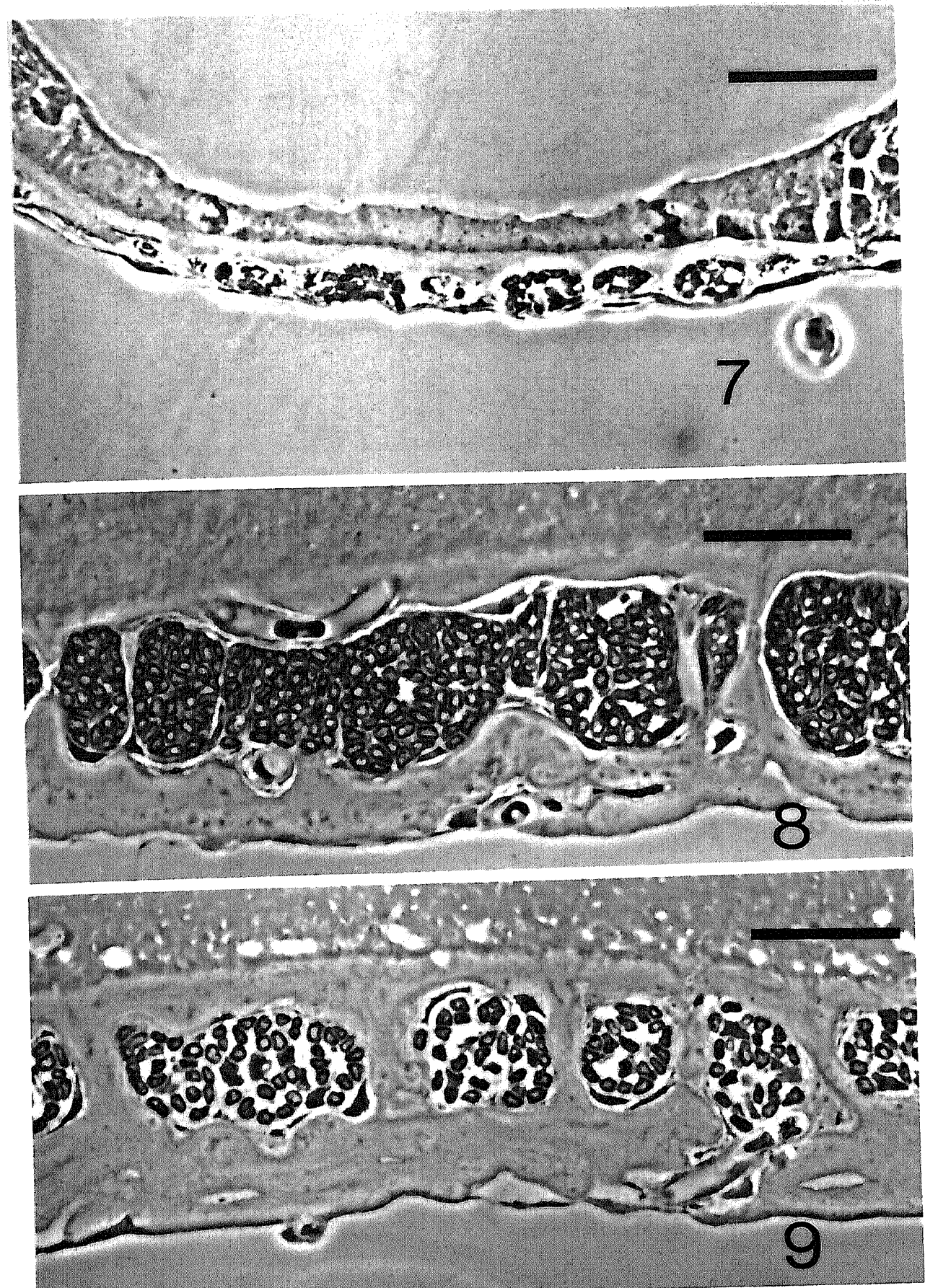

Fig. 7 Tangential section through the osseous spiral lamina (sectioning plane A, fig. 1) at the apex of the throull $\times 800$, marker $\hat{=} 25 \mu \mathrm{m}$

cochlea. Few fibres are running in small bundles. Magnification $\times$, from the Fig. 8 Tangential section through the osseous spiral lamina (sectioning plane fibre bundles are relatively apex. Compared with figures 7 and 9 , here the fibres are densely packed and the fibre bundes cochlea than at the large. It is evident that much more fibres enter the organ of Corti $\triangleq 25 \mu \mathrm{m}$

apex (fig. 7) and at the base (fig. 9). Magnification $\times 800$, marker Fig. 9 Tangential section through the oss 


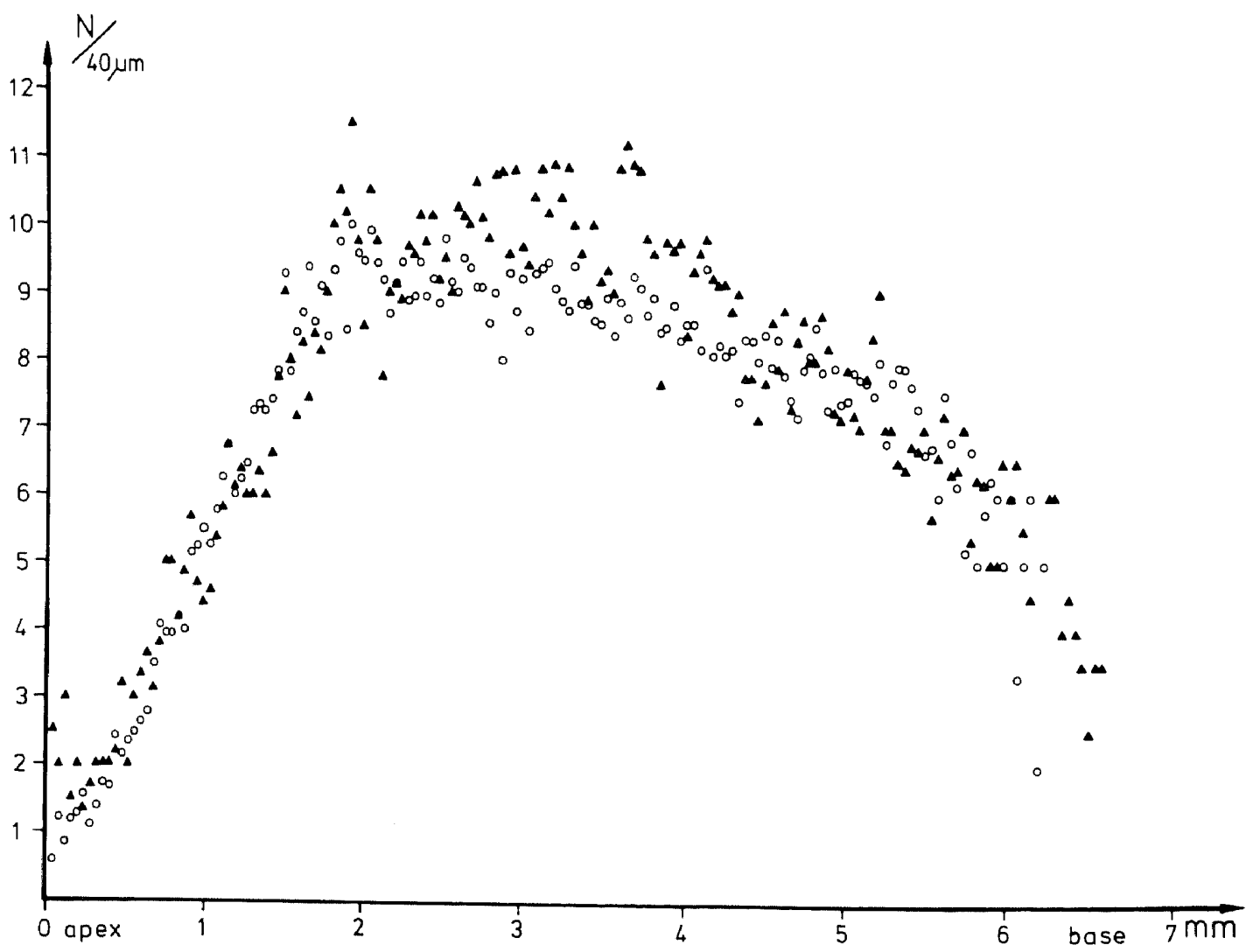

Fig. 10 Densities of upper tunnel radial fibres between apex and base of the cochlea. Ordinate: number (N) of fibres per $40 \mu \mathrm{m}$; abscissa: length of the basilar membrane in $\mathrm{mm}$; open circles: data from surface preparations; closed triangles: data from tangential sections.

cross-sectioned bundle of utrfs. In doubtful cases the number of fibres in a bundle was estimated by the area of the bundle compared with a clearly single fibre in the neighbourhood (fig. 5).

\section{(d) Basilar fibres (bfs)}

Basilar fibres were counted in surface preparations of seven cochleae (fig. 6), and in additional 16 tangentially sectioned cochleae $(8$ osmium and 8 silver-stained) (fig. 1, sectioning plane B; fig. 5). Measurements were only made where bfs were clearly visible over at least $40 \mu \mathrm{m}$.

(e) Fibres before the habenular openings

These fibres, which represent all fibres entering the organ of Corti, were counted in ten tangentially sectioned cochleae stained with osmium (fig. 1, sectioning plane A; figs. 7-9).

\section{Photography}

Microphotographs were taken with a Zeiss photomicroscope III. In all cases an Ilford PAN F film, 50 ASA, was used.

\section{RESULTS}

\section{Number of fibres within the cochlear nerve}

The mean fibre number calculated from six cochlear nerves (without vestibular fibres) was 12,578 with a standard deviation of \pm 819. The mean area of the transversely sectioned cochlear nerve amounts to $0.1341 \pm$ $0.0118 \mathrm{~mm}^{2}$. It was measured near the entrance to the cochlear capsule. Both values allow calculation of the mean diameter of a cochlear fibre, which is $3.7 \mu \mathrm{m}$.

\section{Distribution and total number of upper tunnel radial fibres}

Figure 10 shows the means of the counts 


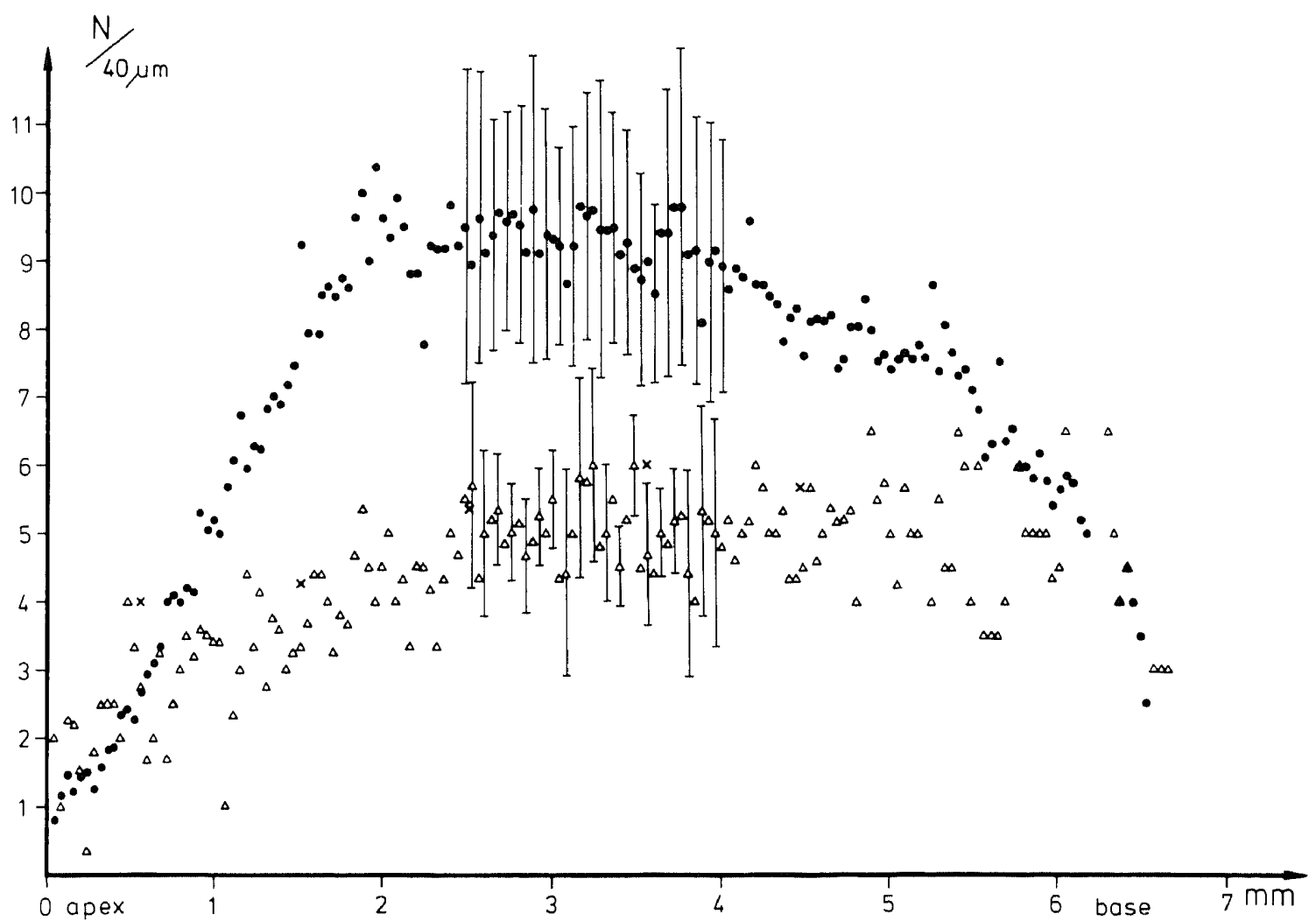

Fig. 11 Densities of upper tunnel radial (efferent) fibres (averaged values of surface preparations and tangential sections; closed circles) and of basilar (afferent) fibres (open triangles and crosses) between apex and base of the cochlea. The open triangles show data from tangential sections, the crosses those from surface preparations. Some standard deviations are shown. They are exemplary for the bfs, but are the largest measured ones for utrfs. Ordinate and abscissa same as in figure 10 .

from surface preparations and tangential sections. By the overlap of data it is evident that both methods yield very similar results. In the middle part of the cochlea, counts from tangential sections are usually a little higher than those from surface preparations. The differences, however, are in no case statistically significant $(p \geqslant 0.05)$. Therefore the results of both methods are averaged and plotted in figure 11. It can be seen that the number of utrfs per $40 \mu \mathrm{m}$ increases linearly from the apex up to $2 \mathrm{~mm}$ (10-fold increase), remains on a high level of nearly ten fibres per $40 \mu \mathrm{m}$ up to $4 \mathrm{~mm}$, and then decreases toward the base. One can calculate the total number of utrfs in the cochlea by adding the counts per $40 \mu \mathrm{m}$. The result is 1,867 fibres.

\section{Distribution and total number of basilar fibres}

In figure 11 the means of the counts from tangential sections are plotted. At the same time the few results from surface preparations are presented. Again the results of both methods do not differ significantly ( $p>0.05$ ). In general, the number of bfs increases by a factor of three from the apex up to $3 \mathrm{~mm}$ and remains at a level of about 5.5 fibres per 40 $\mu \mathrm{m}$ almost to the basal end. Adding all bfs per $40 \mu \mathrm{m}$ gives a total of 703 basilar fibres within the cochlea of the house mouse.

\section{Distribution and total number of all fibres entering the organ of Corti}

Figure 12 shows the means of all fibres counted before they entered the organ of Corti through the habenula perforata. In figure 12 , the means are plotted for distances of $80 \mu \mathrm{m}$ to improve the legibility, although the fibres were originally counted every $40 \mu \mathrm{m}$. There is a significant absolute $(\mathrm{p}<0.01)$ maximum fibre density at $3.7 \mathrm{~mm}$ from the apex. From 


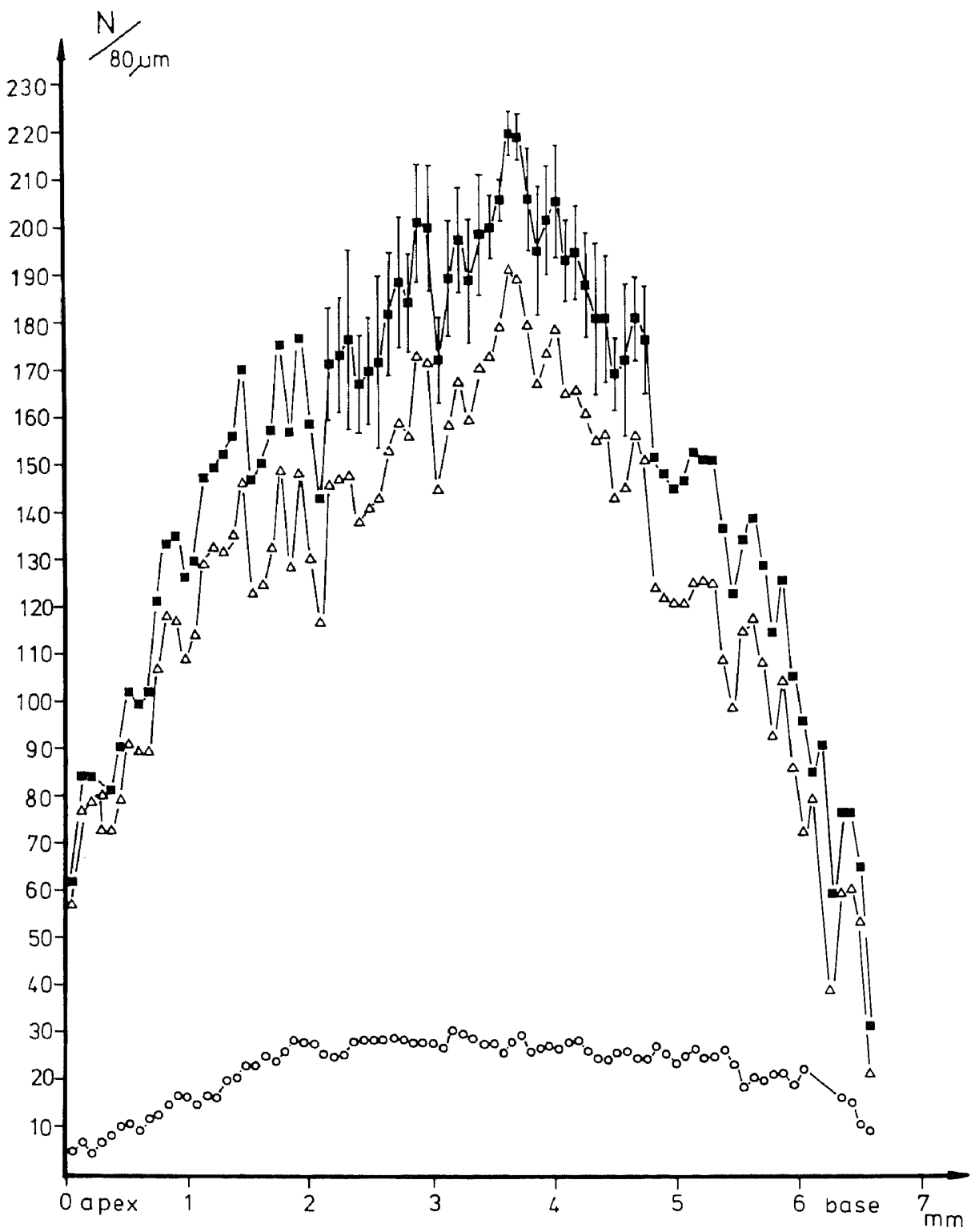

Fig. 12 Densities of all fibres entering the organ of Corti (closed squares), of fibres to the inner hair cells (open triangles), and of fibres (afferents + efferents) to the outer hair cells (open circles) along the cochlea. In the middle of the cochlea standard deviations for all fibres entering the organ of Corti are exemplarily shown. Ordinate: number $(\mathrm{N})$ of fibres per $80 \mu \mathrm{m}$; abscissa: length of the basilar membrane in mm.

there the fibre density decreases rapidly toward the base to a value of only one-seventh of the maximum. The decrease toward the apex is slower. It runs through a significant ( $p$ $<0.01$ ) relative maximum at $2.9 \mathrm{~mm}$ and through oscillations between 1.4 and $2.1 \mathrm{~mm}$. The value at the apex is about 3.5 times lower than the absolute maximum. Adding all counts per $80 \mu \mathrm{m}$, the total number of fibres entering the organ of Corti is $12,350 \pm 810$.

\section{Distribution and total number of fibres running to the inner hair cells}

Densities of fibres innervating the inner 
TABLE 1

Number of fibres in the cochlea of the house mouse

\begin{tabular}{|c|c|c|c|}
\hline & \multicolumn{2}{|c|}{ Number of fibres to the } & \multirow[b]{2}{*}{$\Sigma$} \\
\hline & Inner hair cells & Outer hair cells & \\
\hline $\begin{array}{l}\text { Total } \\
\text { Afferents } \\
\text { Efferents }\end{array}$ & $\begin{array}{c}9,780=79 \% \\
(9,780) \\
?\end{array}$ & $\begin{array}{r}2,570 \doteq 21 \% \\
703 \doteq 6 \% \\
1,867 \doteq 15 \%\end{array}$ & $\begin{array}{c}12,350=100 \% \\
(10,483) \\
(1,867)\end{array}$ \\
\hline
\end{tabular}

hair cells were not directly measured. They can be calculated from figure 12 by subtracting the number of fibres innervating the outer hair cells from the total number of fibres. The result is shown by the open triangles which form a curve running almost parallel to the density curve of all fibres entering the organ of Corti. Conversely, this means that the number and distribution of all fibres entering the organ of Corti is largely determined by those innervating the inner hair cells. The total number of fibres running to the inner hair cells is 9,780 .

\section{Relations between the numbers of fibres to the inner and outer hair cells}

Table 1 shows the division of the total number of fibres which enter the organ of Corti into fibres to the inner and outer hair cells. Assuming the total number of fibres to the outer hair cells is $100 \%$, there are $27 \%$ afferents (basilar fibres) and $73 \%$ efferents (upper tunnel radial fibres). Supposing that all the counted fibres innervating the inner hair cells are afferents, they represent $93 \%$ of all afferent fibres entering the organ of Corti. The remaining $7 \%$ afferents innervate the outer hair cells.

Table 1 illustrates that the great majority of fibres in the cochlea innervate the inner hair cells. This is especially true for the middle part of the cochlea (fig. 12).

\section{DISCUSSION \\ 1. Methods of measurement and reliability of data}

In the present study $6.64 \mathrm{~mm}$ of the cochlea of the mouse could be evaluated. The length of the basilar membrane of the house mouse has already been determined as $6.84 \pm 16 \mathrm{~mm}$ (Ehret and Frankenreiter, '77). The good agreement between the values shows that the measurement of lengths (which is crucial for the determination of the relation between fibre density and place within the cochlea) is reliable. Another crucial point is the method of measuring the number of nerve fibres within a given cochlear segment of $40 \mu \mathrm{m}$. The reliability of fibre counts is proved by the excellent agreement between the total number of fibres within the cochlear nerve and the total number of fibres entering the organ of Corti. Both values were measured independently. Further, the agreement between fibre counts from surface preparations and tangential sections demonstrates the consistency of the present results. Finally, there is a good agreement of the course of the total fibre distribution along the cochlea (fig. 12) with the previously measured distribution of opening areas of habenular openings (Ehret and Frankenreiter, '77). The distances from the apex of absolute and relative maxima of both functions are almost equal $(3.7 \mathrm{~mm}$, respectively $2.9 \mathrm{~mm}$ in both functions). This shows, on the other hand, that the measurement of areas of habenular openings along the cochlea can provide a relative measure of the total fibre density.

\section{Innervation densities of hair cells}

Distributions of the density of nerve fibres along the cochlea are not necessarily equal to the innervation densities of hair cells. If, however, fibre and hair cell densities are known, a rough estimation of innervation densities can be established. The result of such a formal calculation which is based on present and previous measurements (Ehret and Frankenreiter, 77), is shown in figure 13. The differences in innervation patterns between inner and outer hair cells are obvious. There is a pronounced divergent innervation of the inner hair cells whereby, depending on the location within the cochlea, one hair cell is connected with 7-19 single fibres (assuming monosynaptic contacts). The highest density of innervation is found between 3.5 and $4 \mathrm{~mm}$ from the apex (18-19 fibres per cell), and it decreases toward apex ( 8 -9 fibres per cell) and base ( 7 fibres per cell). It has been shown in cats (Spoendlin, '70) and guinea pigs (Morrison et al., '75) that 

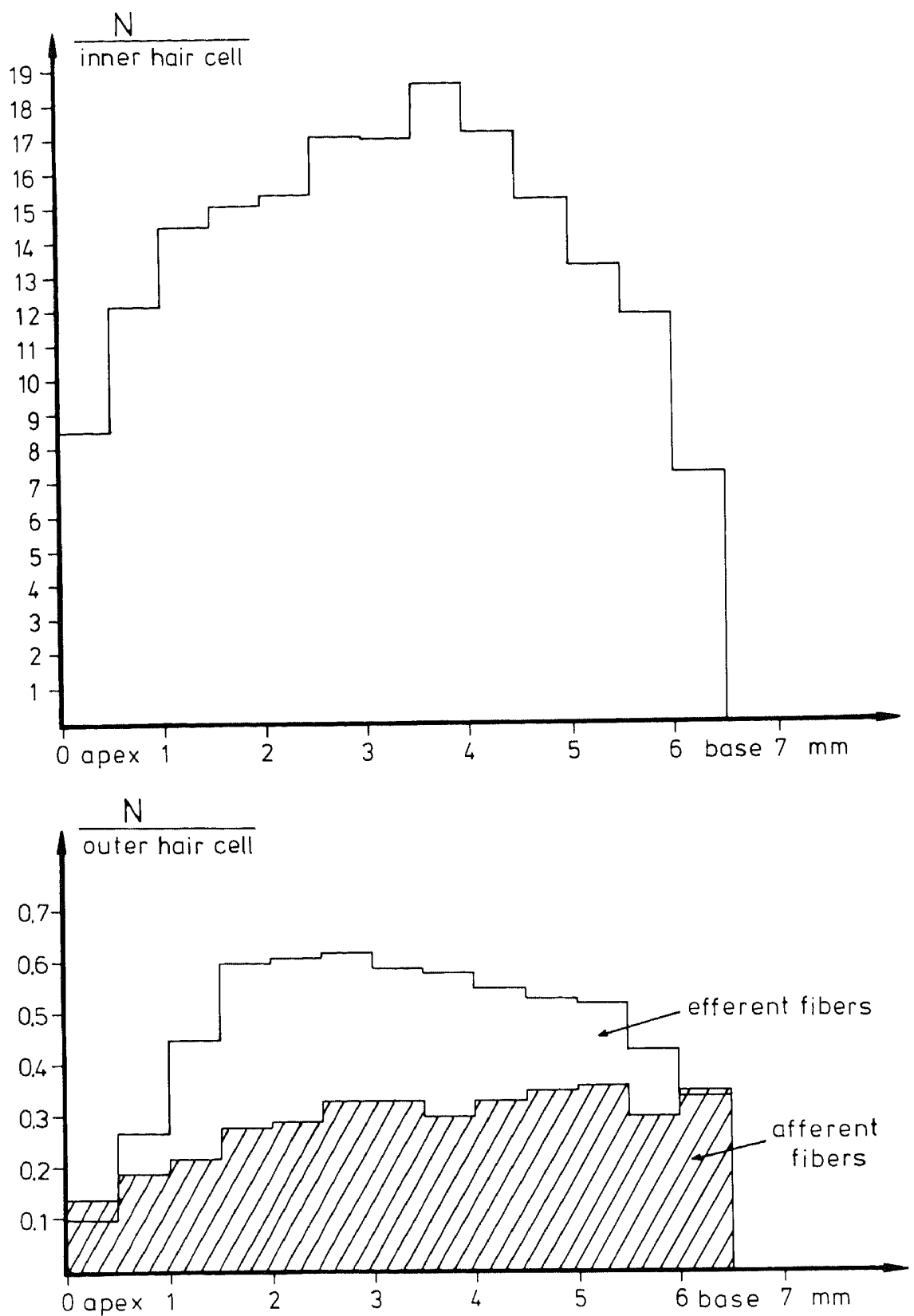

Fig. 13 Innervation densities of inner and outer hair cells between apex and base of the cochlea. The values always show the means for $500 \mu \mathrm{m}$ sectors of the basilar membrane. Ordinate: number $(\mathrm{N})$ of fibres per hair cell; abscissa: length of basilar membrane in $\mathrm{mm}$. Further explanations, see text.

the great majority of fibres running to the inner hair cells are afferents, each of which is monosynaptic with inner hair cells. Provided that this is also true for the mouse, the affer- ent innervation of the inner hair cells would not be uniform along the cochlea. There is a pronounced maximum in the middle of the cochlea, where more than twice as many affer- 
ent fibres would innervate one hair cell than at apex and base. Consequently, the number of information channels from the inner hair cells to the brain is twice as high in the middle of the cochlea as at apex and base.

Figure 13 shows that the outer hair cells have a convergent innervation by both afferent (basilar) and efferent (upper tunnel radial) fibres. In the middle of the cochlea one afferent fibre should be connected with three hair cells and one efferent fibre with two hair cells, assuming that every outer hair cell has at least one afferent and one efferent synapse. The innervation density for both afferent and efferent fibres becomes very low near the apex, which means that the number of outer hair cells connected to one fibre increases. This certainly must be expected for afferent fibres, because one should require at least one afferent synapse to one outer hair cell. Another possibility would be that there is no innervation in some hair cells. It has been demonstrated (Engström, '58; Smith and Sjostrand, '61) that, in fact, the efferent innervation of outer hair cells is partly lacking near the apex and especially in the second and third row. Therefore the decrease in the density of efferent fibres toward the apex (figs. $10,11)$ may involve an increasing number of noninnervated outer hair cells. This is supported by present observations. Near the apex (fig. 3) often space (in the order of some hair cells) is left between the branching areas of neighbouring efferent fibres, so that a considerable number of outer hair cells most probably have no efferent innervation.

\section{Comparison of fibre numbers and distributions within the cochlea of mammals}

The basilar membrane of the mouse is very short $(6.84 \mathrm{~mm})$ compared with guinea pig (20 $\mathrm{mm}$ ), cat $(22 \mathrm{~mm})$, and man $(32 \mathrm{~mm}$ ); (for references see Ehret, '77). Consequently, the mouse has the smallest number of hair cells and of nerve fibres within the cochlear nerve (mouse: 12,578, present study; guinea pig: 24,011, cat: 51,755, Gacek and Rasmussen, '61; man: 31,000, Rasmussen, '40). Obviously the lengths of the receptor areas (basilar membranes) and the number of the cochlear fibres in the mentioned mammals and man are not proportional to each other. Setting the values for the mouse equal to one, the relation between the lengths of the basilar membranes is about $1: 2.9: 3.2: 4.7$, between cochlear fibres, however, the relation is $1: 1.9: 4.2: 2.65$. It is evident that, compared with the mouse, the total fibre density within the cochlea is lower in guinea pig and man and higher in cats. The question arises, whether there are differences in mammals concerning the numerical relation of the different kinds of fibres and their spatial distribution. Figure 14 provides a first approach to the answer to this question. Both cat and mouse have absolute maxima of total fibre densities in the very middle of their cochleae. The total fibre number in the cat is about 1.5 times higher than that in the mouse, but this is only true for the middle and basal part of the cochlea. In the respective apical region, the mouse has more fibres per $200 \mu \mathrm{m}$ than the cat. Because the densities of nerve fibres running to the outer hair cells are almost equal, the additional fibres in the cat innervate the inner hair cells and, according to Spoendlin ('70), are afferents. The densities of afferent (basilar) fibres innervating the outer hair cells are very similar in the three mammals (fig. 14). This is also true for the courses of basilar fibres within the organ of Corti. The fibres cross the tunnel of Corti at the floor and run basalward for $0.6-0.7 \mathrm{~mm}$ in the cat (Spoendlin, '70), and for about $0.5 \mathrm{~mm}$ in the guinea pig (Morrison et al., '75) before they make synaptic contacts. In the present surface preparations of the cochlea of the mouse bfs could be traced basalward for about $0.4 \mathrm{~mm}$. This was, however, only the distinguishable part of the fibre and not its total length (compare fig. 6).

From Spoendlin's data ('72, '73) one can calculate the percent of fibres running to the inner hair cells (about $84 \%$ ) and to the outer hair cells $(16 \%)$ in the cat. In addition, Spoendlin ('72, '73) showed that $95 \%$ of all the afferents innervate the inner hair cells and only $5 \%$ the outer hair cells. The results of the present counts for the mouse are almost the same (table 1). In the guinea pig 85-90\% of the afferent innervation is related to the inner hair cells and 10-15\% to the outer hair cells (Morrison et al., '75). Consequently, the great majority of afferent fibres in all three mammals innervate the inner hair cells, which represent only one-fourth of the total receptor population. This remarkable result indicates very different functions of inner and outer hair cells in sound processing. On the other hand, this kind of different innervation pattern of the hair cells seems to be common within mammals and independent of the 


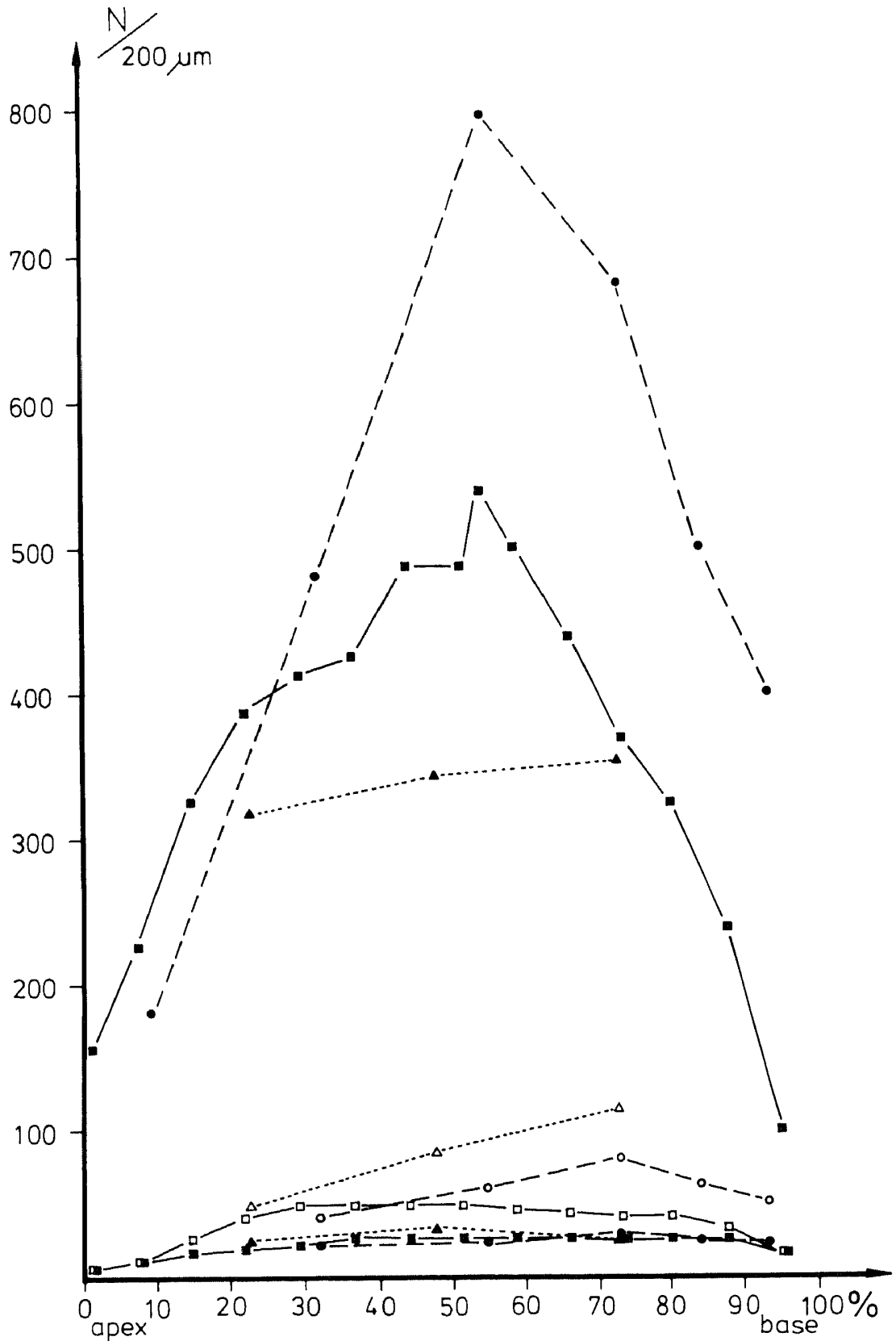

Fig. 14 Comparison of nerve fibre densities in the cochlea of the house mouse (squares), cat (circles), and guinea pig (triangles). Upper filled symbols: densities of all fibres entering the organ of Corti; lower filled symbols: densities of basilar (afferent) fibres to the outer hair cells; open symbols: densities of upper tunnel radial (efferent) fibres to the outer hair cells. Ordinate: number (N) of fibres per $200 \mu \mathrm{m}$; abscissa: distances on the basilar membranes expressed in percent of their respective total lengths. Basal end $\hat{=} 100 \%$. References and explanations, see text. 
length of the cochlea. In addition, relative distances from the apex and not the total lengths of the basilar membranes seem to be related to fibre densities. This is a further indication that the cochlea of mammals are scale models of each other (Greenwood, '61; Ehret, '77).

\section{Functional implications of fibre distributions and innervation densities}

The outer hair cells with their convergent innervation pattern, i.e., several hair cells are connected with one afferent fibre, provide the possibility for summation of receptor outputs. Thus, the sensitivity of afferents from the outer hair cells could be higher than that of afferents of the inner hair cells. Therefore, one could assume that the absolute auditory threshold is determined by the output of the outer hair cells. The comparison of absolute threshold curves of cats (Neff and Hind, '55; Elliott et al., '60) and of house mice (Ehret, 74) with the curves of afferent fibre densities of the outer hair cells (Spoendlin, '72; present study: figs. 11, 13) demonstrates, however, conspicuous differences, so that a direct relation is unlikely. The absolute threshold curves have pronounced maxima of sensitivity. A large variation is also found among thresholds at different frequencies, which is lacking in the density curves of fibres running to the outer hair cells. The density curves of fibres innervating the inner hair cells, however, are shaped similarly to the absolute threshold curves in cat and mouse. If one considers, however, that the shape of the absolute threshold curve of the cat is mainly the result of characteristics of the outer and the middle ear (Dallos, '73), the afferent innervation pattern of the inner hair cells may not determine the course of the absolute threshold curve; it is appropriate to be used for coding the dynamic range of the input. The different afferent fibres which contribute to the multiple innervation of inner hair cells must only have different response thresholds. This could work very well, especially in the middle of the cochlea, where highest sensitivity, largest dynamic range, and highest fibre density appear.

Frequency discrimination may also be influenced by fibre density and innervation pattern. According to the place principle for frequency coding within the cochlea, the divergent afferent innervation of inner hair cells harmonizes better with small detectable fre- quency differences than the convergent innervation of outer hair cells. Actually, Nienhuys and Clark ('78) showed that difference limens of frequency are related to the function of the inner hair cells; the outer hair cells were damaged in animals with normal frequency difference limens.

Critical bands, which play an important role in complex sound analysis (e.g. masking, loudness summation, tonal consonance) cover geometrically equal distances along the basilar membrane (Zwicker and Feldtkeller, '67; Ehret, '76, '77). This uniformity of critical bands corresponds to the uniform afferent innervation of the outer hair cells. There is also a close agreement between the distance which an afferent (basilar) fibre runs toward the base of the cochlea without synaptic contacts (0.5-0.7 mm), and the width of a critical masking band, which varies, depending on the method of measurement between $0.6-1.0 \mathrm{~mm}$ (Ehret, '76, '77).

\section{ACKNOWLEDGMENTS}

This study was supported by the Deutsche Forschungsgemeinschaft, Eh 53/1/3, and $\mathrm{Ma}$ 374/8. I wish to thank Mrs. M. Frankenreiter for her excellent technical assistance.

\section{LITERATURE CITED}

Dallos, P. 1973 The Auditory Periphery. Acad. Press, New York.

Ehret, G. 1974 Age-dependent hearing loss in normal hearing mice. Naturwissenschaften, 61: 506.

- 1975a Frequency and intensity difference limens and nonlinearities in the ear of the house mouse (Mus musculus). J. comp. Physiol., 102: 321-336.

1975b Masked auditory thresholds, critical ratios, and scales of the basilar membrane of the house mouse (Mus musculus). J. comp. Physiol., 103: 329-341. mouse 1976 Critical bands and filter characteristics in the ear of the house mouse (Mus musculus). Biol. Cybernetics, 24: 35-42.

1977 Comparative psychoacoustics: Perspectives of peripheral sound analysis in mammals. Naturwissenschaften, 64: 461-470.

Ehret, G., and M. Frankenreiter 1977 Quantitative analysis of cochlear structures in the house mouse in relation to mechanisms of acoustical information processing. J. comp. Physiol., 122: 65-85.

Elliott, D. N., L. Stein and M. J. Harrison 1960 Determination of absolute-intensity thresholds and frequency-difference thresholds in cats. J. Acoust. Soc. Am., 32:

380-384.
Engström, H. 1958 On the double innervation of sensory epithelia of the inner ear. Acta Otolaryng., 49: 109-118. Fernandez, C. 1951 The innervation of the cochlea (guinea pig). Laryngoscope, 61: 1152-1172.

Gacek, R. R., and G. L. Rasmussen 1961 Fibre analysis of the statoacoustic nerve of guinea pig, cat, and monkey. Anat. Rec., 139: 455.463. 
Greenwood D. D. 1961 Critical bandwidth and frequency coordinates of the basilar membrane. J. Acoust. Soc. Am., 33: 1344-1356.

Lorente de Nó, R. 1937 The sensory endings in the cochlea. Laryngoscope, 47: 373-377.

Morrison, D., R. A. Schindler and J. Wersäll 1975 A quantitative analysis of the afferent innervation of the organ of Corti in guinea pig. Acta Otolaryng., 79: 11-23.

Neff, W. D., and J. E. Hind 1955 Auditory thresholds of the cat. J. Acoust. Soc. Am., 27: 480-483.

Nienhuys, T. G. W., and G. M. Clark 1978 Frequency discrimination following selective destruction of cochlear inner and outer hair cells. Science, 199: 1356-1357.

Perkins, R. E., and D. K. Morest 1975 A study of cochlear innervation patterns in cats and rats with the Golgi method and Nomarski optics. J. Comp. Neur., 163: 129-158.

Rasmussen, A. T. 1940 Studies of the VIIIth cranial nerve of man. Laryngoscope, 50: 67.83 .

Smith, C. A. 1975 Innervation of the cochlea of the guinea pig by use of the Golgi stain. Ann. Otol., 84: 443-458.
Smith, C. A., and F. Sjostrand 1961 Structure of the nerve external hair cells of the guinea pig cochlea as studied by serial sections. J. Ultrastruct. Res., 5: 523-556.

Spoendlin, H. 1970 Structural basis of peripheral frequency analysis. In: Frequency Analysis and Periodicity Detection in Hearing. R. Plomp and G. F. Smoorenburg, eds. Sijthoff, Leiden, pp. 2-36.

eds. Sijthoff Lechlea. Acta Otolaryng., 73: 235-248.

1973 cochlear receptor. In: Basic Mechanisms in Hearing. A. R. Møller, ed. Acad. Press, New York, pp. 185-234,

Press, N., and R. R. Gacek 1963 Electronmicroscopic poendlin, $H .$, and $R$. study of the efferent and ann. Otol. Rhinol. Laryngol, 72: 660-686.

Wright, Ch.G. 1975 Cochlear innervation in the guinea pig. I. The inner spiral bundle region. Acta Otolaryng., 80: 220-229.

Zwicker, E., and R. Feldtkeller 1967 Das Ohr als Nachrichtenempfänger. Hirzel, Stuttgart. 